women with fractured wrists. Thus the inverse relation between bone mineral density and risk of peripheral fracture that has been observed in postmenopausal women ${ }^{134}$ apparently also applies to premenopausal women. Whether our patients were compared with their age matched controls or with the larger group of premenopausal women previously reported on $^{2}$ their bone density was significantly reduced. The close agreement between the mean bone mineral density in the controls in this study and in the previously reported group, despite the difference in mean age, also supports our previous conclusion that bone mineral density does not decrease with age in normal premenopausal women. ${ }^{2}$

An inverse relation between bone density and risk of both vertebral and peripheral fracture has been reported, ${ }^{13.5}$ but as far as we know this is the first time that bone density has been measured and found to be low in premenopausal women with fractures. Earlier work on this subject was dominated by the concept of a fracture threshold and by the high incidence of fractures in postmenopausal women. We suggest that there is no fracture threshold and that the lower the bone density, even if it is within the normal range, the higher the risk of fracture.

We thank Mrs M Marucci for typing the manuscript.

1 Nordin BEC, Chatterton BE, Walker CJ, Wishart J. The relation of forearm mineral density to peripheral fractures in postmenopausal women. Med $\mathcal{f}$ Aust 1987;146:300-4.

2 Nordin BEC, Chatterton BE, Steurer T, Walker CJ. Forearm bone mineral content does not decline with age in premenopausal women. Clin Ortho 1986;211:252-6.

3 Nordin BEC, Wishart JM, Horowitz M, Need AG, Bridges M, Bellon M. The relation between forearm and vertebral density and fractures in postmenopausal women. Bone and Mineral (in press).

4 Wasnich RD, Ross OD, Heilbrun LK, Vogel JM, Yano K, Benfante RJ. Differential effects of thizide and estrogen upon bone mineral content and Difere

5 Out SM, Kilcoyne RF, Chesnut CJ. Ability of four different techniques of measuring bone mass to diagnose vertebral fractures in postmenopausal women. Fourmal of Bone and Mineral Research 1987;2:201-10.

(Accepted 10 August 1988

\section{Burn to toddler's penis from an electrochemical battery}

\author{
I K Mecrow
}

Musgrove Park Hospital, Taunton, Somerset TA1 5DA

I K Mecrow, MRCP, paediatric registrar
There have been several reports of the ingestion of small button batteries by children. ${ }^{1-3}$ To my knowledge burns due to prolonged contact of larger high voltage batteries with the skin have not been reported before.

\section{Case report}

A 19 month old toddler was admitted to hospital from the casualty department with a part circumferential full thickness burn to the ventrolateral aspect of the penis. This had been discovered when his nappy (which was damp and had been worn for around five hours), was removed, when a $9 \mathrm{~V}$ battery had been found wedged at the base of the penis with both terminals in contact with the skin. Two circular, confluent full thickness burns had been sustained, each measuring $1.5 \mathrm{~cm}$ across. A green deposit was seen around one of these, and the penis was inflamed and oedematous. The results of a general examination were normal, and no evidence of abuse, either physical or sexual was found. After surgical debridement of necrotic tissue the burns were dressed with sulphadiazine. Three months later healing was complete with no deformity of the penile shaft.

\section{Comment}

On the day before admission the child's mother had been teaching him to place objects in his trouser pockets. Probably in mimicking this he placed a battery inside his nappy. The battery had both terminals at one end, and when he urinated an electrical circuit was completed and the burn was sustained. He gave no indication of discomfort and apparently had no pain. Although non-accidental injury or sexual abuse seemed unlikely, the parents were interviewed and social work reports compiled. No evidence was found to support these diagnoses.

The risks of ingestion of small objects such as button batteries are generally understood by parents. ${ }^{3}$ Larger batteries, particularly when worn out, are, however, considered harmless and are occasionally given to small children to play with. These may cause burns if prolonged contact with the skin occurs, and they are therefore unsuitable for this purpose.

1 Temple DM, McNeese MC. Hazards of battery ingestion. Pediatrics 1983;71 $100-3$

2 Litoritz TL. Button battery ingestion. IAMA 1983;249:2495-500.

3 Kiely B, Gill D. Ingestion of button batteries, hazards, and management. BrMed f 1986;293:308.

(Accepted 24 August 1988
Ealing Hospital, Southall, Middlesex UB1 3 HW

Diana N Lockwood, MRCP, medical registrar

Michael J Trand, MIEEIE,

head of medical electronics

Hugh M Mather, MD,

consultant physician

Correspondence to: $\mathrm{Dr}$ Mather.

\section{Is injecting air into insulin bottles necessary?}

\author{
Diana N Lockwood, Michael J Trand, \\ Hugh M Mather
}

Patients treated with insulin are taught to inject an exact volume of air into the bottle before drawing up insulin to avoid creating a partial vacuum. This complicated manoeuvre may be difficult to master, especially when two bottles are being used. We suspected that it is unnecessary because insulin can easily be withdrawn without adding air despite the vacuum. We therefore monitored serial pressures inside bottles when withdrawing insulin without adding air, and we measured pressures in bottles used by patients and nurses.

\section{Methods and results}

Pressures were measured by inserting into the bottle a needle attached to a Druck PDCR75 transducer through a reservoir of water. The system was calibrated with a precision meter, and readings were within $5 \%$ (mean $2 \cdot 8 \%$ ) over the range -93 to $93 \mathrm{kPa}$ (relative to atmospheric pressure). Readings were made in duplicate in random order at room temperature. Firstly, we measured serial pressures inside six bottles of insulin after withdrawing aliquots of $0.25 \mathrm{ml}(25$ units) with a $0.5 \mathrm{ml}$ syringe without adding air Secondly, we measured the pressure in partly used bottles containing $0 \cdot 5-9 \cdot 0 \mathrm{ml}$ (mean $5 \cdot 0$ ), which were provided by 81 randomly selected patients (aged 9-83). 